\title{
Pipeline repair by composite patch under temperature and pressure loading
}

\author{
E. Abdelouahed, H. Benzaama \\ Laboratoire LABAB, Ecole Nationale Polytechnique Maurice Audin, Oran, Algeria \\ beabamine@gmail.com, babenza@yahoo.fr
}

\author{
M. Mokhtari \\ Laboratoire LaRTFM, Ecole Nationale Polytechnique Maurice Audin, Oran, Algeria \\ mokbtarimohamed44@yahoo.fr \\ B. Aour \\ Laboratoire LABAB, Ecole Nationale Polytechnique Maurice Audin, Oran, Algeria \\ ben_aour@yahoo.fr
}

\begin{abstract}
In this study, the three-dimensional finite element method is used to analyze an API 5L X70 steel cylindrical pipeline subjected to an internal pressure load by calculating the stress intensity factors and the integral $\mathrm{J}$ at the peak of crack in elastic and elastoplastic behavior. The effectiveness of composite patch repair bonded to the cracked surface is highlighted. The effects of the geometrical and mechanical properties of the composite patch and the adhesive on the effectiveness of the repair were highlighted. The variation of the stress intensity factor at the crack tip is used to evaluate the repair performance. The results obtained show that the residual heat stress significantly increases the stress intensity factor at the bottom of the crack, which reduces the effectiveness of the repair.

KEYwORDS. FEM; Repair by composite patch; Pipeline; Cracking; Thermal stress; Internal pressure; Temperature; Stress intensity factor.
\end{abstract}

\section{OPEN ACCESS}

Citation: E. Abdelouahed, H. Benzaama, M. Mokhtari, B. Aour, Pipeline repair by composite patch under temperature and pressure loading, Frattura ed Integrità Strutturale, 49 (2019) 690-697.

Received: 21.04 .2019

Accepted: 15.05 .2019

Published: 01.07.2019

Copyright: (C) 2019 This is an open access article under the terms of the CC-BY 4.0, which permits unrestricted use, distribution, and reproduction in any medium, provided the original author and source are credited.

\section{INTRODUCTION}

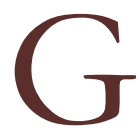
lobal energy demands continue to rise with the rapid development of the global economy. [1] Pipeline transportation of oil and gas is the safest and cheapest way for hydrocarbon transportation companies. [2] To increase the profitability of a pipeline, the flow is often increased by increasing the service pressure. [3]

Considerable research work is available in the literature on the various aspects of bonded composite joints. Several design parameters play an important role in the technology of composite patches, [4] such as patch size, patch shape, material selection, patch, ambient temperature, size of heating zones, etc.., the importance and effects of some of the design parameters discussed. 
For pipeline repair, a number of technical design issues must be considered that may be important depending on the repair circumstances. The application of a bonded repair to a pipeline poses a number of technical design problems with materials that may be important depending on the circumstances of repair. [5] One example is the development of residual stresses when a high cure temperature adhesive is used to bond a repair patch to a substrate with a different coefficient of thermal expansion. [6] The main drawback of the use of gr / ep (graphite / epoxy), b / ep (boron / epoxy) and g / p (glass / epoxy) results from a discrepancy in the coefficients of thermal expansion between the composite and the metal. [7] Residual thermal stresses are particularly important when high temperature curing adhesives are used to bond the patch.

For example, in a typical repair applied to pipeline structures, the reinforced region is initially heated to a temperature of about $100-120^{\circ} \mathrm{C}$ under pressure for about 1 hour and then cooled to room temperature after curing of the adhesive. 8] Due to the differences between the elastic properties and the thermal expansion properties of the composite patch and the metallic pipeline, residual thermal stresses may occur. It has long been recognized that in some cases, residual heat stress is a serious problem for the effectiveness of composite patch repair. [9] If the repair material is different from the substrate, the residual stress level must be calculated during the design process. [10]

Numerous attempts have been made in recent years to estimate the values of these residual stresses. Köpple et al. [11] used an analytical method based on linear elastic fracture mechanics and finite element method and considered a steel pipeline with a through-wall defect repaired by a composite material. Zarrinzadeh et al. [12] used the ABAQUS software to better simulate the experimental results of cracked aluminum pipe with patch repair under fatigue load. T. Nateche et al. [13] used a composite patch to repair damaged pipelines. It is a fast and economical method without interruption of service.

Mhamdia et al. [14] analyzed the effects of residual thermal stress on the variation of the stress intensity factor in an aluminum plate repaired with a composite boron / epoxy patch.

According to Albedah et al. [15] the residual thermal stress caused the reduction of the fatigue life of repaired aeronautical structures. To mitigate the effects of residual heat stress on repair performance, cure temperature and adhesive properties must be optimized. Lam et al. [16] also considered a circular tube that is repaired by a composite patch to study the effect of the patch on reducing stress intensity factors.

The purpose of this study is to analyze the effect of the variation of the stress stress factor of repaired crack in steel pipelines with aadhesived composite patch. The novelties of this work are the parametric studies of the effects of the geometric, thermal and mechanical properties of the composite on the variation of the stress intensity factor at the end of cracks repaired with aadhesived composite patch.

\section{FINITE ELEMENT MODEL}

$\mathrm{T}$ he cracked steel pipeline that is repaired by a composite patch under an internal pressure load as shown in Fig. 1. The API 5L X70 elastic cylindrical steel pipeline having the following dimensions: $\mathrm{D}_{\text {pipe }}=304,8 \mathrm{~mm}, \mathrm{~L}_{\mathrm{pipe}}=1000 \mathrm{~mm}$, $\mathrm{e}_{\text {pipe }}=4 \mathrm{~mm}$. A transverse crack of length $2 \mathrm{a}$ to the pipe axis is assumed to exist in the pipeline. This crack is repaired with a composite patch of boron / epoxy $2 \mathrm{~mm}$ thick, and length 4a. The adhesive used for bonding is FM-73 with a thickness $\mathrm{e}_{\mathrm{a}}=0.2 \mathrm{~mm}$, inside diameter equal to the outside diameter of composite patch. The inside diameter of the composite patch is equal to the outside diameter of the pipeline. The adhesive is cured at $120^{\circ} \mathrm{C}$ and the ambient temperature is considered to be $20^{\circ} \mathrm{C}$. The elastic and thermal properties of the pipeline and the composite are given in Tab.1.

Analysis by the finite element method of the configuration illustrated in Fig. 1 is performed using the calculation code ABAQUS [17]. In order to avoid the degrees of complexity in the finite element model of this three-dimensional structure, we have formulated some simplifying assumptions that allowed us to capture the essential characteristics of the response. These assumptions are: - each part of the model is considered as a three-dimensional structure. no bonding property at the interface between the adhesive and the two other structures (pipe, patch). at the interface, each mesh node is common between the adjacent structures. - The adhesive is homogeneous elastic and isotropic [18]. - The deformation of the adhesive is under the effect of shearing and peeling. - The patch is unidirectional composite oriented perpendicular to the crack. The adhesive is modeled as a third layer. The nodes are common between the patch/adhesive and adhesive/pipe interfaces for continuity of deformation and stress. The advantage is to be able to capture the necessary characteristics of the adhesive such as the transfer of charges between the pipe and the patch.

The finite element model consists of three subsections; cracked pipeline, adhesive and composite patch. Due to symmetry, only half of the repaired pipeline is considered. To generate the crack front, a number of elements originally created around the crack tip are replaced by a "crack block". This crack block is meshed with quadratic elements, which are mapped in the space of the original elements and merged with a quadratic mesh. The mesh was refined near the crack end zone using at 
least 10 elements at the front and near the crack tip. We have refined the mesh proportionally to the number of elements which gives the convergence of the results. We used quadratic elements based on quadratic interpolation functions in order to have a low calculation cost. A Gauss point is used per element which allows us to have a reduced integration scheme.

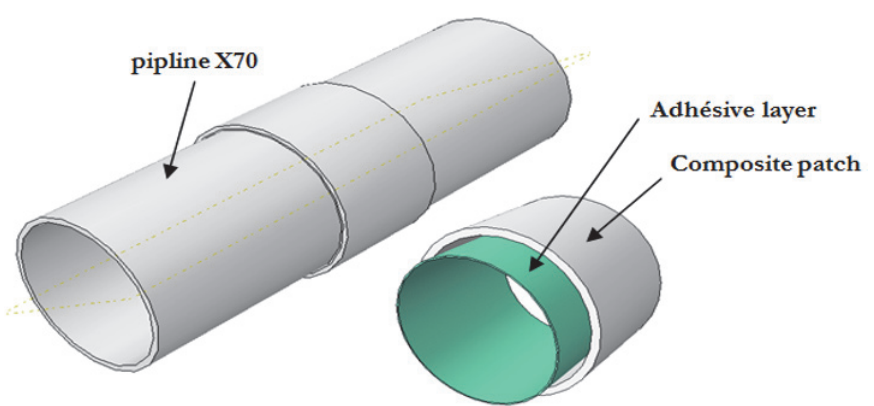

Figure 1: Diagram of a cracked aluminum pipe repaired by composite patch.

\begin{tabular}{|c|c|c|c|c|c|c|c|c|c|c|c|c|}
\hline & $\begin{array}{c}\mathrm{E}_{1} \\
(\mathrm{GPa})\end{array}$ & $\begin{array}{c}\mathrm{E}_{2} \\
(\mathrm{GPa})\end{array}$ & $\begin{array}{c}\mathrm{E}_{3} \\
(\mathrm{GPa})\end{array}$ & $\begin{array}{c}\mathrm{G}_{12} \\
(\mathrm{GPa})\end{array}$ & $\begin{array}{c}\mathrm{G}_{13} \\
(\mathrm{GPa})\end{array}$ & $\begin{array}{c}\mathrm{G}_{23} \\
(\mathrm{GPa})\end{array}$ & $\gamma_{12}$ & $\gamma_{13}$ & $\boldsymbol{\gamma}_{23}$ & $\begin{array}{c}\boldsymbol{\alpha}_{12} \\
\left(10^{\left.-6^{\circ} \mathrm{C}\right)}\right.\end{array}$ & $\begin{array}{c}\boldsymbol{\alpha}_{12} \\
\left(10^{\left.-6^{\circ} \mathrm{C}\right)}\right.\end{array}$ & $\begin{array}{c}\boldsymbol{\alpha}_{12} \\
\left(10^{\left.-6^{\circ} \mathrm{C}\right)}\right.\end{array}$ \\
\hline API 5L X70 & 207 & & & & & & 0.33 & & & 22.5 & & \\
\hline $\begin{array}{l}\text { Adhesive } \\
\text { (FM-73) }\end{array}$ & & & & 0.42 & & & 0.30 & & & & & \\
\hline Bore/époxy & 200 & 19.6 & 19.6 & 7.2 & 5.5 & 5.5 & 0.3 & 0.28 & 0.28 & 4.5 & 23 & 23 \\
\hline Glass/époxy & 50 & 14.5 & 14.5 & 2.56 & 2.56 & 2.24 & 0.33 & 0.33 & 0.33 & 5.5 & 15 & 15 \\
\hline Carbone/époxy & 134 & 10.3 & 10.3 & 5.5 & 5.5 & 3.2 & 0.33 & 0.33 & 0.53 & -1.2 & 34 & 34 \\
\hline
\end{tabular}

Table 1: Elastic and thermal prosperity for different materials

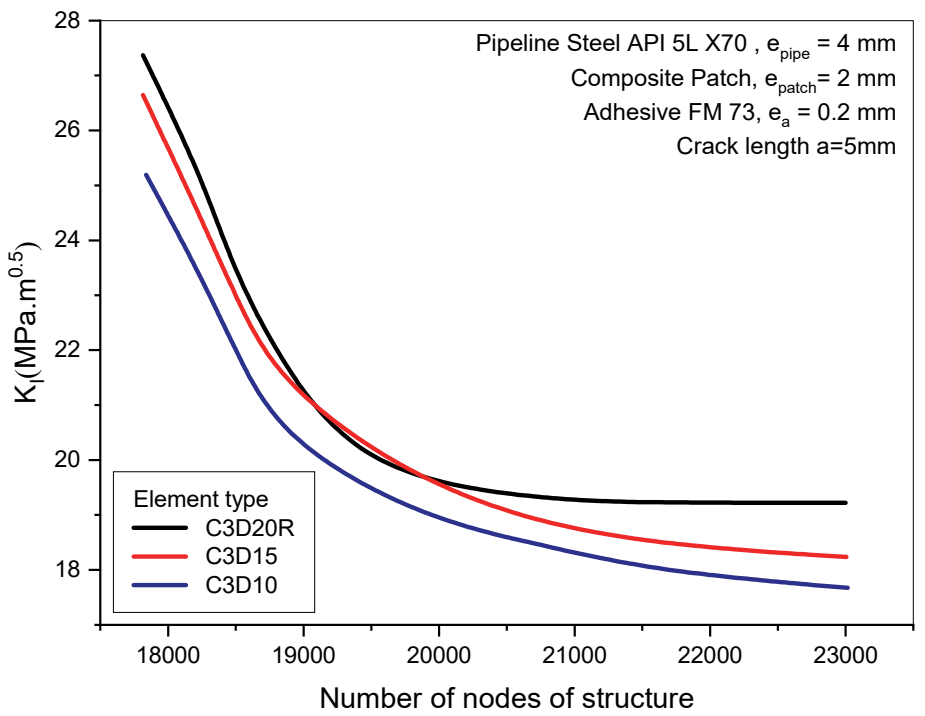

Figure 2: Mesh convergence of the structure. 
The virtual crack closure technique is based on the energy balance proposed by Irwin. In this technique, the stress intensity factors are obtained for the three fracture modes using the equation:

$$
\mathrm{G}_{\mathrm{i}}=\mathrm{K}_{\mathrm{i}}^{2} / \mathrm{E}
$$

where $G_{i}$ is the energy release rate for mode $i, K_{i}$ is the stress intensity factor for mode $i$, and $E$ is the modulus of elasticity (I, II and III).

In numerical elemental computations, the mesh choice results in the number of nodes and their arrangement that characterize the element and its density in the mesh structure. A series of calculation launching is opted in the first places in order to reach the convergence of computation with an optimization in the density of mesh, three different types of mesh were used: C3D20R: (A 20-node quadratic brig), (C3D15 : A 15-node quadratic triangular prism), (C3D10: A 10-node quadratic tetrahedron). Stabilization of the result such as the stress intensity factor expresses the optimal choice of number and type of elements. It is also important to refine the mesh at the crack levels in order to better capture the value of the stress intensity factor. The number of elements used in the structure is 21414 elements in the pipeline, 2176 in the patch and 2176 in the adhesive. Fig. 3 shows the architecture of the mesh used for the calculations.

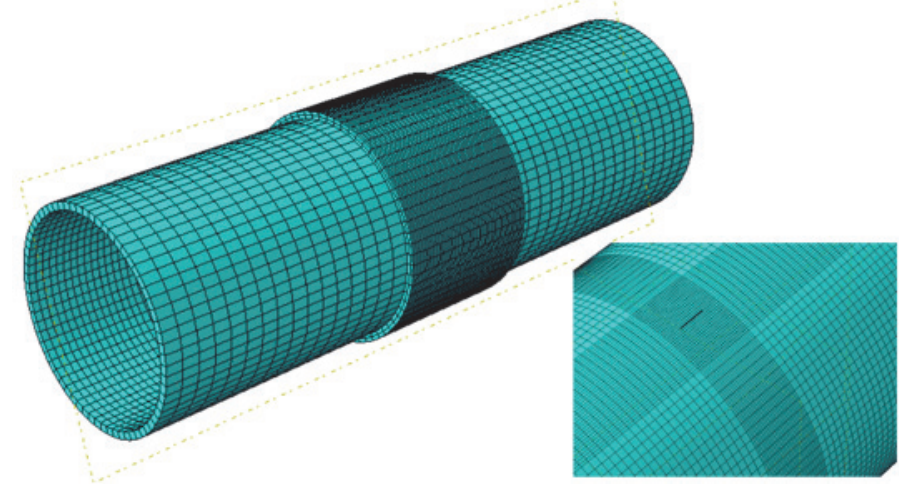

Figure 3: Overall mesh of the sample

\section{RESULTS AND DISCUSSION}

\section{$\mathrm{F}$}

Effect of internal pressure

ig. 4 shows the variation of the stress intensity factor in the cracked and repaired pipeline by three types of composite patch (boron / epoxy, glass / epoxy and carbon / epoxy) as a function of the change in internal pressure in the pipeline rift. The stress intensity factor $(\mathrm{KI})$ is calculated in the direction of the fiber (parallel to the direction of the applied load). We can see that the adhesive curing process involves a relatively high level of SIF at the crack front in the pipeline. This means that the adhesive and the patch are in tension. The pressurized pipeline exerts the tensile stresses. The intensity of the constraints in the patch is less significant compared to the constraint in the pipeline. This is because the coefficient of thermal expansion for steel is greater than that of (boron/epoxy, carbon/epoxy and glass/epoxy). However, the stresses in the composite are relatively large because there is a transfer of stresses from the steel pipeline to the composite part through the adhesive layer. On the other hand, it can also be said that the best composite for repair under high pressures is boron/epoxy.

This linear variation of the stress intensity factor as a function of the internal pressure clearly reflects the linear behavior of the composite patch, the more rigid the composite, the greater the repair.

\section{Temperature effect}

Fig. 5 uses the variation of the stress intensity factor in the cracked and repaired pipeline by three different types of composite patches (boron / epoxy, glass / epoxy and carbon / epoxy) as a function of the temperature in the external environment of the composite cracked pipeline. We notice that the stress intensity factor is higher when the temperature increases; it means that the increase of the temperature reduces the quality of the repair. From the graph (Fig. 4), it can be said that among the 
three composites, boron / epoxy and the most resistant patch in areas where the temperature is high for the repair of cracked transport pipelines.

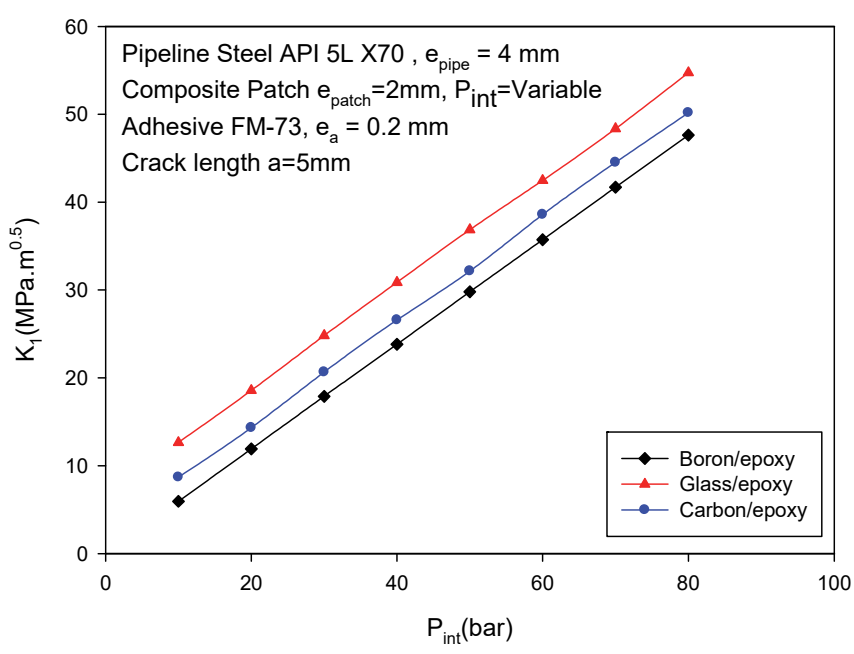

Figure 4: SIF variation according to the internal pressure

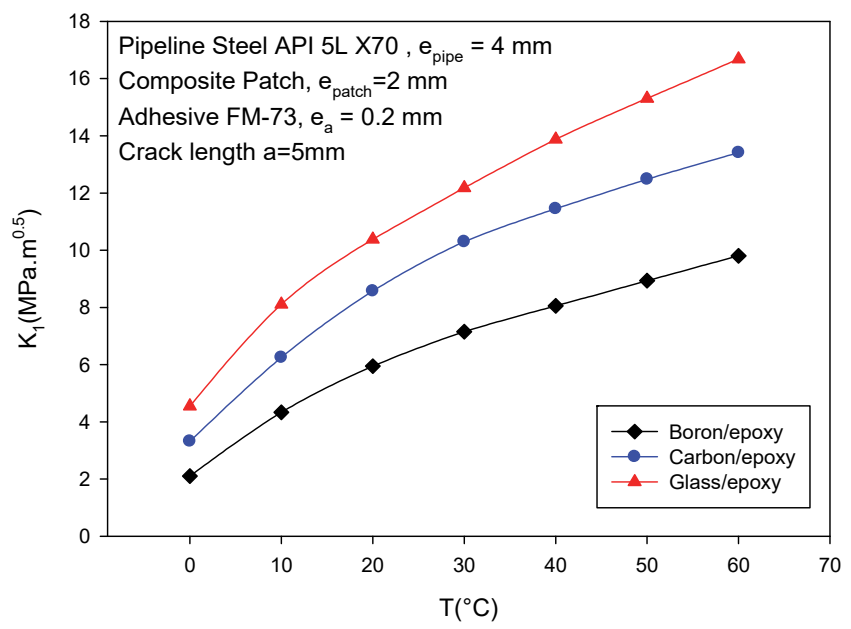

Figure 5: SIF variation according to the temperature of the external environment

The temperature of the external environment as well as the type of the patch composite clearly played a determining effect on the stress intensity factor levels. On one side the temperature weaken the adhesive accumulating the load on the pipeline and on the other hand the quality of the composite of the patches conditions the absorbed quantity of the loads, the more the composite is rigid more it allows the adhesive to transfer more than charge. However, this transfer is limited by the capacity of the adhesive, which will be limited even more by the presence of temperature as a climatic load on the structure.

\section{Effect of crack depth}

Fig. 6 shows the evolution of the stress intensity factor at the bottom of the composite patch repaired API 5L X70 steel pipe crack as a function of the crack depth change with respect to the thickness of the pipeline. We noticed that the KI increases when increasing the depth of the emerged crack, so the stresses are very important at the front of the crack. It is deduced that the quality of the repair decreases in cases where the crack is very deep.

It is also noted that the effect of the composite quality of the patch follows the same variation as that of the stress intensity factor. This effect also retains the advantage of its quality regardless of the parameters analyzed. The more the crack depth increases, the more the repair affects its effect. 


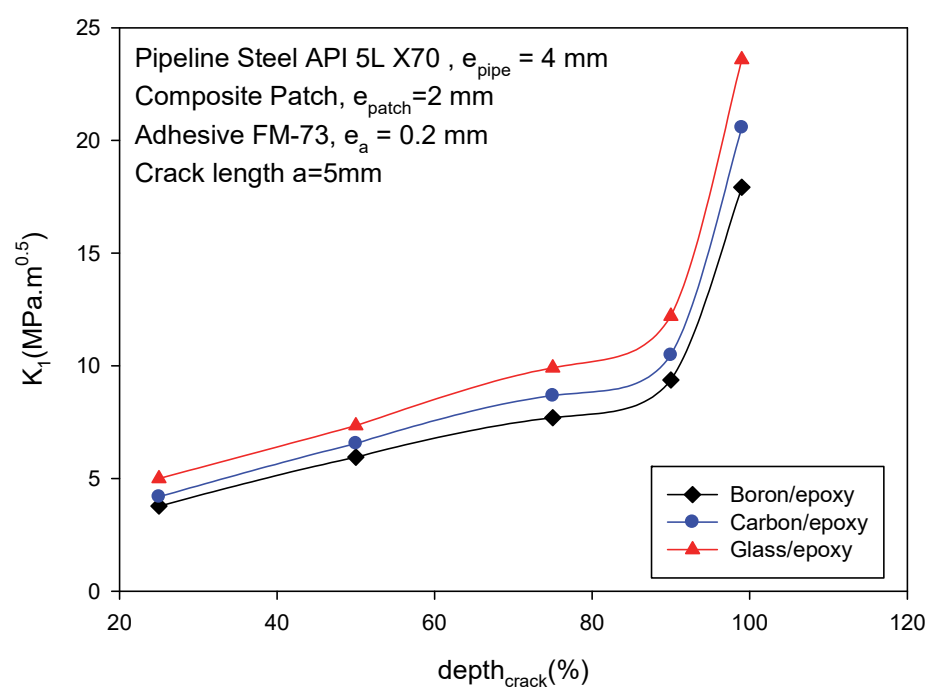

Figure 6: Variation of SIF as a function of the crack depth of the pipeline

\section{Effect of the thickness of the patch}

Fig. 7 shows the evolution of the stress intensity factor at the crack front of the repaired steel pipe API 5L X70 as a function of the thickness variation of the composite part independently of the boron/epoxy, the glass/epoxy or carbon/epoxy. We note that the $\mathrm{K}_{\mathrm{I}}$ decreases as the thickness of the patch increases in the three different cases of repair and the smallest value is when the thickness of the patch is equal to the thickness of the pipeline.

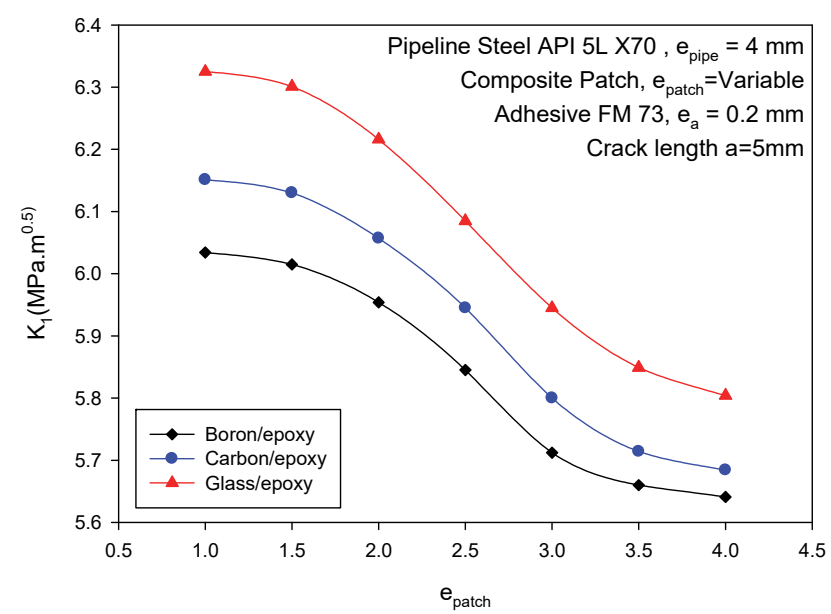

Figure 7: SIF variation according to composite patch thickness

Likewise, the reduction of the stress intensity factor follows the same variation as a function of the thickness of the patch, and always keeps the advantage of its quality (boron, carbon, glass) between them. The more the patch increases in thickness, the greater the charge transfer by the adhesive. This considerably reduces the SIF, but remains conditioned by the strength of the adhesive.

\section{Effect of change in crack length}

Fig. 8 shows the variation of the stress intensity factor at the crack front in a pipeline repaired by three different types of composite patches (boron/epoxy, glass/epoxy and carbon/epoxy) as a function of the length of the crack.

From this Fig. 5, we notice that the development of the crack gives us larger values of $\mathrm{K}_{\mathrm{I}}$, which means that the quality of the repair by composite patches decreases. We also note that the most effective material for repair in case of long cracks is boron/epoxy. Reducing the stress intensity factor is always possible with a more rigid composite choice but it is clearly 
shown in this figure that the more the crack increases the more the repair becomes useless. This can be explained by the fact that the working area (transfer) of the adhesive is limited when the crack increases.

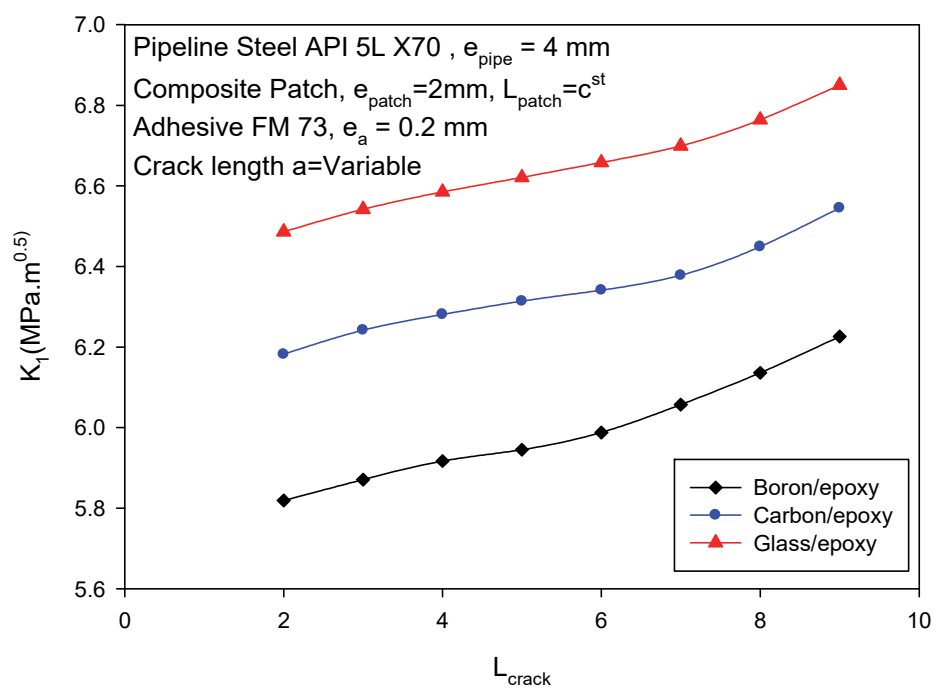

Figure 8: SIF variation according to the crack length of the pipeline

\section{CONCLUSION}

7 his study has been focused by a numerical simulation on the evaluation of the stress intensity factor under different effect of: temperature variation, pressure variation, patch variation, patch thickness variation, and crack size variation of a structure steel pipe cracked and repaired by composite patch. The following conclusions could be deduced from the obtained results:

- Patches and adhesive play a crucial role on the repair. Any reduction efficiency is limited by the ability of the adhesive to resist.

- The efficiency repair is directly related to the stiffness of the composite patch. If the composite is more rigid, the repair efficiency is elevated.

- An increase in the thickness of the patch increases the rigidity, the consequence, the increase in the efficiency.

- The reparation efficiency decreases with the increasing length and crack depth. Which subsequently undermines the work of the adhesive.

- Thermal stresses weaken the capacity of the adhesive by accumulating loads, which explains the increase in the stress intensity factor.

\section{REFERENCES}

[1] Manne, A., Mendelsohn, R., Richels, R. (1995). A model for evaluating regional and global effects of GHG reduction policies, Energy Policy, 23 (1), pp. 17-34.

[2] Sydney, T., Richard A. D. (2003). Review of ways to transport natural gas energy from countries which do not need the gas for domestic use, Energy, (28), pp. 1461-1477.

[3] Ibrahim, H., Ilinca, A., Perron, J. (2008). Energy storage systems-Characteristics and comparisons, Renewable and Sustainable Energy Reviews, (12), pp. 1221 - 1250.

[4] Katnam, K.B., Da Silva, L.F.M., Young, T.M. (2013). Bonded repair of composite aircraf t structures: A review of scientific challenges and opportunities, Progress in Aerospace Sciences, (61), pp. 26-42.

[5] Wu, M., Johannesson, B., Geiker, M. (2012). A review: Self-healing in cementitious materials and engineered cementitious composite as a self-healing material, Construction and Building Materials, (28), pp. 571-583.

[6] Djokic, D., Rogers, A., Lee-Sullivan, P., Mrad, N. (2002). Residual stress development during the composite patch bonding process: measurement and modeling, Composites, (A33), pp. 277-288. 
[7] Baker, A. (1999). Bonded composite repair of fatigue-cracked primary aircraft structure, Composite Structures, (47), pp. 431-443.

[8] Komonen, J., Penttala, V. (2003). Effects of High Temperature on the Pore Structure and Strength of Plain and Polypropylene Fiber Reinforced Cement Pastes, Fire Technology, (39), pp. 23-34.

[9] Chow, W. T., Atlim, S. N. (1997). Composite Patch Repairs of Metal Structures: Adhesive Nonlinearity, Thermal Cycling, and Debonding, AIAA Journal, 35 (9), pp. 1528-1535.

[10] Gu, D.D., Meiners, W., Wissenbach, K., Poprawe, R. (2012). Laser additive manufacturing of metallic components: materials, processes and mechanisms, International Materials Reviews, 57 (3), pp. 133-164.

[11] Köpple, M., Lauterbach, S., Wagner W. (2013). Composite repair of through-wall defects in pipework -Analytical and numerical models with respect to ISO/TS 24817, Compos. Struct, (95), pp. $173-178$.

[12] Zarrinzadeh, H., Kabir, M.Z., Deylami, A. (2017). Crack growth and debonding analysis of an aluminum pipe repaired by composite patch under fatigue loading, Thin-Walled Structures, (112), pp. 140-148.

[13] Nateche, T., HadjMeliani, M., Shafique, M.A., Khan, Matvienko, Y.G., Merah, N., Pluvinage, G. (2015). Residual harmfulness of a defect after repairing by a composite patch, Engineering Failure Analysis, (48), pp. 166-173.

[14] Mhamdia, R., Bachir Bouadjra, B., Serier, B. et al. (2011). Contrainte intensity factor for repaired crack with bonded composite patch under thermo-mechanical loading. J Reinf Plastic Compos, (30), pp. 416-424.

[15] Albedah, A., Bachir Bouiadjra, B., Aminallah, L., et al. (2011). Numerical analysis of the effect of thermal residual contraintees on the performances of bonded composite repairs in aircraft structures. Compos, B (4), pp.511-516.

[16] Lam, C., Cheng, J., Yam, C. (2011). Finite element study of cracked steel circular tube repaired by FRP patching, Procedia Eng, (14), pp. $1106-1113$.

[17] ABAQUS finite element programs. ABAQUS Standard 5.6. Hibbitt. Pawtucket, RI 028: Karlsson and Sorensen, Inc.

[18] Madani, K., Touzain, S., Feaugas, X., Cohendouz, S., Ratwani ,M. (2010). Experimental and numerical study of repair techniques for panels with geometrical discontinuities. Computational Materials Science, (48), pp. 83-93. 